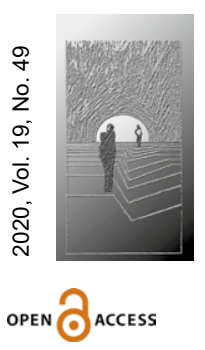

Zbigniew Treppa

http://orcid.org/0000-0002-5974-689X Uniwersytet Gdański Instytut Mediów, Dziennikarstwa i Komunikacji Społecznej zbigniewtreppa@icloud.com

Karolina Aszyk

http://orcid.org/0000-0003-0891-8919 Uniwersytet Gdański

Instytut Mediów, Dziennikarstwa i Komunikacji Społecznej karolinaaszyk@icloud.com DOI: 10.35765/hw.1780

\title{
Nowe modele kulturowe w World Press Photo a problematyka rodzinna
}

\section{STRESZCZENIE}

CEL NAUKOWY: Celem artykułu jest określenie, w jaki sposób za pomocą fotografii prezentuje się w mediach publicznych zagadnienia dotyczące nowych modeli kulturowych, przede wszystkim w odniesieniu do problematyki rodzinnej, która na poziomie komunikatów werbalnych jest kontestowana lub poddawana manipulacjom.

PROBLEM I METODY BADAWCZE: Stawiając problem, konieczne stało się uzyskanie odpowiedzi na pytanie, czy w fotografii rozumianej jako medium informacji zaanonsowane zagadnienia kształtowane są podobnie jak w komunikatach werbalnych. Posłużono się narzędziami semiotyki obrazu, uwzględniającej dwa typy analiz: semantyczną i syntaktyczną.

PROCES WYWODU: Badania, których efekty zostały zamieszczone w artykule, koncentrowały się na analizie nagrodzonych prac w najbardziej prestiżowym dla świata mediów konkursie World Press Photo. W artykule zamieszczono wyniki analiz prac podlegających ocenie jury World Press Photo w 2015 r., które są najbardziej wyrazistym odzwierciedleniem występujących w mediach napięć dotyczących podjętego tematu. W toku analizy ukazano, w jaki sposób dokonuje się manipulacji podczas oceniania fotografii zgłoszonych do konkursu.

WYNIKI ANALIZY NAUKOWEJ: Z przeprowadzonej analizy wynika, że prezentacja w mediach publicznych nowych modeli kulturowych za pośrednictwem fotografii odbywa się z naruszeniem reguł przyjmowanych dotąd jako standardowe. Chociaż na gruncie fotografii prasowej na poziomie dokonywania ocen czyni się wysiłki zmierzające do degradowania wizerunku rodziny, to na poziomie samego obrazu wizerunek rodziny nie podlega degradacji.

WNIOSKI, INNOWACJE, REKOMENDACJE: Nowe modele kulturowe prezentowane są w mediach według reguł nieuczciwej promocji, co odbywa się kosztem obniżenia rangi innych nośnych społecznie zagadnień. Fotografia prasowa jest jednak bardziej odporna na manipulacje niż przekazy słowne. Wynika to z właściwości samej fotografii dokumentalnej, którą dużo trudniej manipulować na poziomie struktury znaczeniowej aniżeli w przypadku analogicznych przekazów werbalnych.

\section{$\rightarrow$ SŁOWA KLUCZOWE: JĘZYK OBRAZU, KOMUNIKAT WIZUALNY, KODOWANIE ZNACZEŃ}




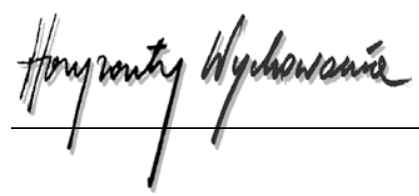

\section{ABSTRACT \\ New Cultural Models in the Context of Family Issues from the Perspective of the World Press Photo Awards}

RESEARCH OBJECTIVE: The aim of the article is to determine how photography shows issues related to new cultural models in public media, primarily in relation to family issues, which at the level of verbal messages is contested or manipulated.

THE RESEARCH PROBLEM AND METHODS: When posing the problem, it became necessary to answer the question whether in photography understood as a medium of information, the reported issues are shaped similarly to verbal messages. Image semiotics tools were used, taking into account two types of analysis: semantic and syntactic.

THE PROCESS OF ARGUMENTATION: The research, whose effects were included in the article, focused on the analysis of the awarded works in the World Press Photo competition, the most prestigious for the world of media. The article contains the results of analyzes of works subject to assessment by the World Press Photo jury in 2015, which turned out to be the most expressive reflection of the tensions in the media regarding the topic taken up. The analysis shows how manipulation is carried out during the evaluation of photos sent to the competition.

RESEARCH RESULTS: The analysis shows that the presentation in the public media of new cultural models through photography takes place in violation of the rules adopted so far as standard. Although in press photography, at the level of making assessments, efforts are made to degrade the image of the family, at the level of the image itself, the image of the family is not subject to degradation.

CONCLUSIONS, INNOVATIONS, AND RECOMMENDATIONS: New cultural models are presented in the media according to the rules of unfair promotion, which is done at the expense of lowering the rank of other socially relevant issues. However, press photography is more resistant to manipulation than verbal messages. This is due to the properties of documentary photography itself, which is much more difficult to manipulate at the level of semantic structure than in the case of analogical verbal messages.

$\rightarrow$ KEYWORDS: IMAGE LANGUAGE, VISUAL MESSAGE, CODING OF MEANINGS

\section{Wprowadzenie}

Ze wstępnych spostrzeżeń wynika, że problematyka nowych modeli kulturowych prezentowana w mediach publicznych w arbitralny sposób wypiera wiele istotnych zagadnień o charakterze społecznym, w tym problematykę rodzinną. Przeprowadzając analizę tego zjawiska na gruncie fotografii prasowej, konieczne wydaje się uzyskanie odpowiedzi na pytanie, czy w fotografii rozumianej jako medium informacji zaanonsowane zagadnienia kształtowane są podobnie jak w komunikatach werbalnych, w których poddawane 
są kontestacji wartości reprezentatywne dla tradycyjnie rozumianej rodziny, m.in. przez manipulowanie faktami na jej temat, przy jednoczesnym nachalnym promowaniu alternatywnych modeli kulturowych. Wydaje się, że jak dotąd nie przeprowadzono podobnych badań, biorąc za przedmiot obserwacji sferę wizualną mediów publicznych, wśród których fotografia odgrywa ogromną rolę.

\section{Cel naukowy i założenie badawcze}

Celem naukowym naszych badań jest określenie, w jaki sposób za pomocą fotografii prezentuje się w mediach publicznych zagadnienia dotyczące nowych modeli kulturowych, zwłaszcza w odniesieniu do problematyki rodzinnej.

Na początku badań stawiamy następującą tezę: problemy współczesnej rodziny ukazywane w fotografii prasowej podlegają wpływom manipulacji medialnych podobnie jak w innego rodzaju komunikatach medialnych, choć w znacząco mniejszym stopniu, natomiast promowanie w tym obszarze alternatywnych modeli kulturowych odbywa się głównie na poziomie komentarzy werbalnych zastosowanych wobec obrazu. Teza, którą postawiliśmy, mogła się zrodzić dzięki świadomości istnienia specyfiki i odrębności obrazu jako medium przekazywania treści. Nadmienić należy, że specyficzne cechy fotografii jako medium, dzięki adekwatnie zastosowanym narzędziom badawczym, już wielokrotnie w przeszłości pozwoliły ujawnić jej odporność na negatywne wpływy i manipulacje ze strony nadawców komunikatów medialnych. Ten właśnie fakt skłonił nas do przeanalizowania podjętego tematu z perspektywy stosowanych przez nas metod badawczych.

\section{Źródła badawcze oraz metody i narzędzia badawcze}

Nasze badania koncentrowały się na analizie nagrodzonych prac w najbardziej prestiżowym dla świata mediów konkursie World Press Photo, które były wykonywane od roku 2000 do roku 2018. Poddaliśmy więc badaniom najbardziej reprezentatywne dla mediów fotografie pochodzące z obecnego stulecia ${ }^{1}$. Bazując na badaniach kilkuset prac, w niniejszym artykule przedstawiamy analizy fotografii podlegających ocenie jury w 2015 r., które okazały się najbardziej wyrazistym odzwierciedleniem występujących w mediach napięć dotyczących podjętego tematu. Materiały źródłowe do naszych analiz zaczerpnęliśmy z oficjalnej strony internetowej World Press Photo, która posiada profesjonalne archiwum wszystkich edycji konkursu.

\footnotetext{
${ }^{1}$ Odnośnie do wagi wydarzenia, jakim jest World Press Photo, z danych za rok 2019 wynika, że przyciągnął on ponad 5000 uczestników z około 125 krajów, którzy łącznie przesłali do oceny 95000 zdjęć (https://www.worldpressphoto.org/programs/contests/photo-contest/history/28612, dostęp: 09.08.2019).
} 


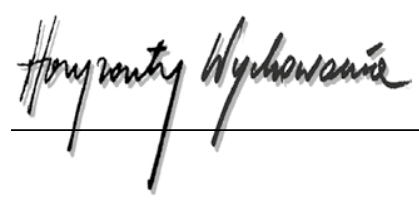

Nasz cel badawczy można było osiągnąć dzięki współczesnej wiedzy na temat właściwości języka obrazu. Powyższe właściwości tego języka stają się dopiero czytelne dzięki zastosowaniu odpowiednich metod badawczych. Biorąc pod uwagę specyfikę podjętego tematu, istnieją poważne racje, by spojrzeć na obraz, bazując na współczesnych metodach analizy obrazu, która postrzega go jako medium służące do porozumiewania się. W naszej pracy zastosowaliśmy przede wszystkim narzędzia semiotyki obrazu. Uwzględnia ona kilka typów analiz: semantyczną, syntaktyczną i pragmatyczną, które posiadają szeroki zakres badań i charakteryzowania wartości utworu. Metoda semiotyczna odniesiona do obrazu bazuje na modelu, którego zręby swojego czasu zaproponował prof. Mieczysław Porębski w swojej pracy Sztuka a informacja (Porębski, 1986).

Od lat 50. poprzedniego stulecia, kiedy Rudolf Arnheim sformułował w swojej fundamentalnej pracy Myślenie wzrokowe zręby nowoczesnej teorii obrazu, w przestrzeni publicznej nastąpiło wiele zmian dotyczących rozumienia roli obrazu w aktywności człowieka i w życiu społecznym, które na najbardziej elementarnym poziomie należy określić jako przechodzenie z pozycji emocjonalnych, wrażeniowych i intuicyjnych na rozumne i intelektualne (Arnheim, 2011). Jedna z zasad Arnheima opiera się na szerokiej regule dotyczącej zmysłów - nie tylko wzroku - mówiącej o tym, że „wrażliwość zmysłów na bodźce docierające z otoczenia jest rozumna" (Arnheim, 2011, s. 27). Dla naszych rozważań jedna z myśli tego badacza będzie wyznaczać kierunek naszej argumentacji: „Percepcja i myślenie (...) współdziałają ze sobą: nasze myśli wpływają na to co widzimy, i vice versa" (Arnheim, 2011, s. 25). W świetle powyższego wychodzimy z założenia, że traktując obraz jako świadomy przekaz informacji (w taki sposób rozumie się rolę obrazu w szerokiej przestrzeni medialnej), w jego odbiorze należy stosować kategorie racjonalne, intelektualne, nie zaś wyłącznie emocjonalne.

Powyższe nastawienie badawcze umożliwia przeprowadzenie analiz strukturalnych obrazu, co prowadzi do poznania zawartych w jego strukturze znaczeń. Aby w pełni je odczytać, należy również traktować obraz jako kanał przepływu informacji, która dociera do odbiorcy nie tylko poprzez „coś”, co jest widoczne w obrazie w postaci motywów kojarzących się z tym, co postrzegamy w realnej rzeczywistości, ale również poprzez to, w jaki sposób to „coś” zostało w obrazie odzwierciedlone, co na poziomie bardzo ogólnym sprowadzić można do kwestii estetycznych. Stosując narzędzia semiotyki obrazu, nie można pominąć faktu, że forma estetyczna utworu ma ogromny wpływ na ostateczny charakter przekazu, zatem na treść. Chcąc docenić rolę formy obrazu w odbiorze jego treści, zastanówmy się najpierw, jakie jest pochodzenie treści w obrazie fotograficznym.

\section{W jaki sposób jest kodowana i odkodowywana treść w obrazie?}

Odpowiadając na powyższe pytanie, nie można pominąć zagadnienia zależności sfery komunikacyjnej obrazu od estetyki, obraz bowiem (wyłączając nieliczne wyjątki) zawsze jest związany z jakąś estetyczną konwencją obrazowania. Komunikacja za 
pośrednictwem obrazu dokonuje się w dużej mierze dzięki zastosowanym środkom wyrazu, które właśnie tworzą taką konwencję.

Na jakość estetyczną składa się w fotografii wiele jej specyficznych środków wyrazu. To one, oddziaływając bardzo silnie na zmysły, wywołując określony nastrój i związane z nim znaczenia, uprzedzają odbiór intelektualny. Forma w jakimś sensie przygotowuje do odbioru znaczeń. Staje się to oczywiste na gruncie semiotyki obrazu, kiedy bada się oddziaływania formy obrazu na poziomie syntaktycznym. Najbardziej wyrazistym przykładem takiego oddziaływania może być wzajemne oddziaływanie na siebie barw, wywołujących silne emocjonalne bodźce. Jedynie właściwie przeprowadzona analiza obrazu na poziomie syntaktycznym umożliwia dokonanie w odpowiedzialny sposób jego analizy semantycznej. Nieco upraszczając, można powiedzieć, że syntaktyka podprowadza do odbioru treści, które następnie bada semantyka. Patrząc zaś na to zagadnienie z perspektywy niepoddanego analizie odbioru znaczeń, treść obrazu odkodowywana jest przez odbiorcę w pierwszej kolejności na drodze zmysłowej, kiedy np. najpierw „odczuwa się" (bo obraz to wywołuje) smutek, radość, lekkość, poczucie egzystencjalnego ciężaru czy też inne emocjonalne stany.

W obrazie treść w silny sposób uwarunkowana jest zatem formą, co widoczne jest również w fotografii, która posiada bardzo silne związki z rzeczywistością. W przypadku fotografii prasowej na temat tych związków funkcjonuje wiele stereotypów. Jednym z nich jest przekonanie, że treść obrazu „wygenerowana” jest przez sytuację - jej źródłem miałaby być realna rzeczywistość. Taki model pozbawia oczywiście fotografa podmiotowości, redukując jego rolę do funkcji sprawnego ekwilibrysty obsługującego narzędzie do rejestracji obrazu. Taki stereotyp jest wygodnym narzędziem w rękach manipulatorów medialnych i służy do wyrabiania u „konsumentów” obrazu przekonania, że rzeczywistość jest taka, jak ukazał ją fotograf, co oczywiście nie zawsze pokrywa się z rzeczywistym stanem rzeczy.

Analizując nagrodzone prace konkursu World Press Photo, widać jasno, że na wyżynach dokumentu fotograficznego dominuje inny model kodowania znaczeń w obrazie. Oparty jest on na następującym porządku: fotograf najczęściej nieprzypadkowo wybiera medialnie nośną sytuację i nieprzypadkowo koduje w obrazie treści o bardzo określonych, zaplanowanych wcześniej znaczeniach. Realna rzeczywistość w tym modelu jest tylko nośnikiem treści. Sama treść obrazu jest wygenerowana przez fotografa przy jedynie „biernym” współudziale rzeczywistości. Przy takim podejściu do interpretacji dzieła istnieje oczywiście ryzyko jego nadinterpretacji. Może ono jednak zostać zminimalizowane, jeśli w odpowiedzialny sposób posłużyć się narzędziami semiotyki obrazu, które wyżej zostały zaanonsowane.

Zanim posłużymy się tymi narzędziami w odniesieniu do fotografii nagrodzonych w omawianym konkursie, należy sobie uświadomić, że jednym z dwóch kryteriów nagradzania w nim prac jest aktualność problematyki, którą w ostatnim czasie żył świat, co oznacza, że w konkursie może zostać nagrodzona praca, która „reprezentuje wydarzenie lub problem o wielkim znaczeniu dziennikarskim w tym [danym] roku" (https://www. worldpressphoto.org/programs/contests/photo-contest/judging-process/28600, dostęp: 


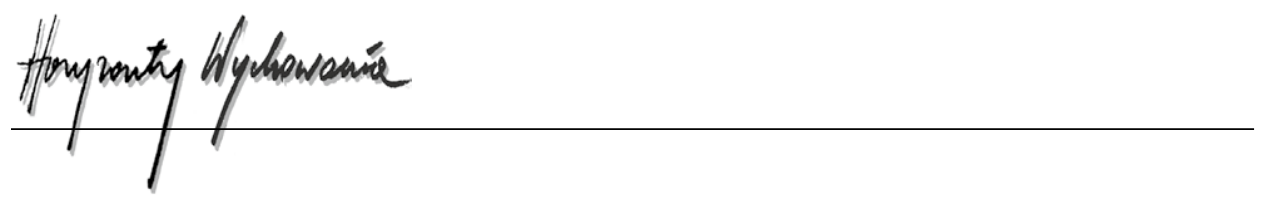

13.08.2019). Określenie w taki sposób jednego z dwóch kryteriów oceny wartości fotografii wydaje się całkowicie zrozumiałe w kontekście konkursu fotografii prasowej jak pokazuje jednak praktyka oceniania prac, nie zawsze jest ono respektowane przez samych oceniających, co pod znakiem zapytania stawia bezstronność ocen członków jury World Press Photo. Kiedy zaś mowa jest o kryteriach oceniania prac, wymieńmy również drugie z nich, które mówi o tym, że zgłaszana praca powinna odzwierciedlać „wizualną kreatywność i umiejętności” fotografa (https://www.worldpressphoto.org/programs/contests/photo-contest/judging-process/28600, dostęp: 13.08.2019). Zastanawiające jest, że w tak prestiżowym konkursie, zadedykowanym najcenniejszym obrazom odzwierciedlającym wydarzenie danego roku, wśród kryteriów oceny wartości obrazów znajduje się jedynie zapis o „połączeniu wartości wiadomości, standardów dziennikarskich oraz kreatywności i umiejętności wizualnych fotografa", brakuje natomiast jakichkolwiek określeń precyzujących oczekiwania jurorów dotyczące formy ocenianych prac czy choćby w jakiś inny sposób odnoszących się wprost do obrazów jako takich. Wydaje się to tym bardziej kuriozalne, jeśli uświadomić sobie, że odzwierciedlanie w pracach „wizualnej kreatywności i umiejętności” fotografa nie precyzuje, do czego owa kreatywność ma się odnosić, co również stwarza ogromne możliwości nadużyć w ocenach.

\section{Jon and Alex, czyli o stronniczości werdyktów służących promocji nowych modeli obyczajowych}

Zapoznając się z ogólnymi zapisami procedur oceniania prac zgłoszonych do tego konkursu, można odnieść wrażenie, że jego organizatorzy dołożyli wszelkich starań, by oceny członków jury były obiektywne i bezstronne. Po szczegółowym zapoznaniu się z regułami procedur widać jasno, że w konkursie World Press Photo ocena wartości fotografii cały czas pozostaje na poziomie emocjonalnym, niemal instynktownym, redukując sferę intelektualną ekspertów oceniających zgłoszone do konkursu prace do intuicji, która może sankcjonować każdą, nawet najbardziej chybioną ocenę. W takiej sytuacji w ocenie wartości danej pracy pozostaje duży margines dowolności, co może skutkować tendencyjnymi decyzjami członków jury, dając możliwość promowania prac, które w danym czasie odzwierciedlają nie tyle ich rzeczywistą wartość, ile np. poglądy określające poprawność polityczną poszczególnych członków komitetu (czy nawet całych gremiów jury) oceniających zgłoszone do konkursu fotografie.

Powyższej oceny nie jest w stanie zmienić fakt, że konkurs składa się z sześciu rund głosowania. Chociaż proces głosowania zakłada, że dla każdej rundy istnieje odrębne jury, to jednak w takim systemie istnieje możliwość generowania błędnych ocen dotyczących przede wszystkim stopniowania nagród, w tym przyznania nagrody głównej. Bierze się to stąd, że najważniejsze decyzje na ostatnim etapie podejmuje jury o składzie, co do którego kryteria nie są jasno ustalone. Po przeanalizowaniu kilkuset nagrodzonych prac w skali 18 analizowanych przez nas edycji konkursu zakładany przez organizatorów obraz wiarygodności i bezstronności ocen pęka jak bańka mydlana. 
Najbardziej skrajnym tego przykładem jest decyzja przyznania przez członków jury World Press Photo głównej nagrody i tym samym ogłoszenia za fotografię roku 2015 pracy zatytułowanej Jon and Alex autorstwa Madsa Nissena. Fotografia ukazuje intymną scenę kontaktu cielesnego dwóch partnerów w „małym apartamencie Alexa w Sankt Petersburgu" (https://www.worldpressphoto.org/programs/contests/photo-contest/winners/2015, dostęp: 26.08.2019). Komentarz objaśniający scenę, który miał przekonać członków jury, że spośród tysięcy fotografii zgłoszonych do konkursu właśnie ta realizacja powinna reprezentować „wydarzenie lub problem o wielkim znaczeniu dziennikarskim” w 2015 r., brzmi następująco: „Jon, 21 lat, i Alex, 25 lat, są parą. Bycie lesbijką, gejem, biseksualistą lub transseksualistą (LGBT) staje się w Rosji coraz trudniejsze". Nadmienić należy, że za treść komentarzy do fotografii jest odpowiedzialna World Press Photo Foundation, która po nominacji danej fotografii do nagrody w przypadku jakichkolwiek wątpliwości dotyczących złamania etyki dziennikarskiej oddelegowuje zespół badawczy do zebrania podstawowych informacji na temat każdego obrazu i jego historii. To właśnie ta fundacja jest odpowiedzialna za treść tekstu komentującego obraz.

Po wszechstronnej analizie nagrodzonej pracy staje się oczywiste, że jury w tym konkretnym przypadku nie dostosowało się nawet do i tak bardzo elastycznych kryteriów obowiązujących go ocen. Pod jego adresem należałoby postawić pytanie, czy enigmatycznie określone „bycie lesbijką, gejem, biseksualistą lub transseksualistą” jako „W Rosji coraz trudniejsze” mogło faktycznie być reprezentatywnym „wydarzeniem lub problemem o wielkim znaczeniu dziennikarskim" dla 2015 r.? Pytanie to o tyle jest zasadne w kontekście takich wydarzeń i zjawisk, które niewątpliwie wówczas elektryzowały świat mediów, jak exodus afrykańskich uchodźców (spośród nich wielu zginęło w falach Morza Śródziemnego), rzezie cywilów: starców, kobiet i dzieci w objętej wojną Syrii, a także operacje militarne Rosji na Ukrainie. Oceniając z perspektywy syntaktyki i semantyki obrazu fotografię, którą jury wybrało jako najbardziej reprezentatywną dla wszystkich wydarzeń prezentowanych w mediach w 2015 r., okazało się również, że w żaden sposób nie pozwala ona odbiorcy na odczytanie zawartych w obrazie znaczeń, które scharakteryzowane zostały przez autora.

Na brak związków obrazu z jego komentarzem, które łącznie według reguł konkursu mają stanowić spójny przekaz, wskazują dominujące w obrazie jego jakości formalne. Są nimi: pozbawione kontrastów oświetlenie oraz łagodna i ciepła w tonacji, złocisto-brunatno-cielesna barwa, wywołujące nastrój pełen liryki i melancholii. Należy docenić wrażliwość autora na barwę i światło, które łącznie wytworzyły ów nastrój.

Obraz ten, nawiązujący w formie i treści do buduarowych scen o tematyce erotycznej mistrzów okresu rokoka, należy zestawić w jednym rzędzie z realizacjami artysty tej miary, co Jean-Honoré Fragonard. Podkreślić jednak należy, że treść przekazu daleko bardziej wynika z substancjalności obrazu aniżeli z dołączonego do fotografii komentarza słownego.

Według reguł komunikacji obrazowej nośnikiem treści obrazu jest w pierwszej kolejności sam obraz, nie zaś jego komentarz. To on przyjmuje główny ciężar przekazu treści. Treść w obrazie wynika bowiem z jego formy, z „substancjalności obrazowego 


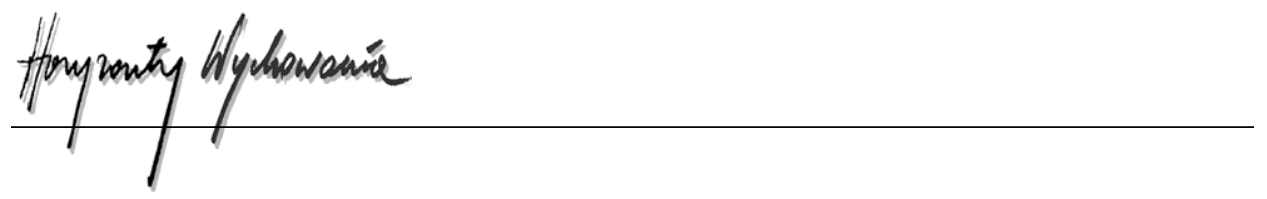

medium”, za pośrednictwem którego przekazywane są jego „kontekstowe znaczenia” (Porębski, 1986, s. 110). Jeśli w komunikacie ikonicznym komentarzowi do obrazu zostaje przyznane pierwszeństwo przed znaczeniami, których obraz jest nośnikiem, tym samym negowane są jego możliwości medialne. Nie sposób zaprzeczyć, że medialne możliwości fotografii Nissena zgłoszonej do konkursu wynikają przede wszystkim stąd, że wygenerowany przez niego obraz z założenia pełni funkcję medium informacji. Jaką informację niesie ten obraz? Oto dzięki autorowi odbiorca staje się świadkiem intymnego zbliżenia pomiędzy kochankami, zdarzenia ukazanego w afirmatywnych kategoriach, które dokonuje się w zaciszu anonimowego buduaru, gdzieś w jakimś nieznanym zakątku świata. Kodując w ten sposób obraz, jego autor nie umożliwił odbiorcy odczytania informacji, że bycie w Rosji osobą w odmienny sposób przeżywającą swoją płciowość aniżeli osoby heteroseksualne jest „coraz trudniejsze”. Sfotografowana przez niego liryczna, „ciepła” scena, nie pozwala jej odbierać w kategoriach dramatycznej wizji, którą autor roztacza za pomocą słów w komentarzu do zdjęcia.

W tym m.in. tkwi problem z oceną tej pracy: słowo komentarza, nie mając odzwierciedlenia w obrazie, stanowiąc rodzaj „protezy” informacyjnej, przejęło główny ciężar przekazu treści, która stała się przyczyną wypromowania obrazu do nagrody głównej konkursu (nie ma wątpliwości, że sama scena zbliżenia pomiędzy kochankami nie mogła udźwignąć ciężaru „wydarzenia lub problemu o wielkim znaczeniu dziennikarskim”). Podczas 18 analizowanych przez nas edycji konkursu bazującego na twardych faktach wyartykułowanych mową obrazu, nie zaś słowa, nie zdarzyło się, aby praca wyróżniona tytułem fotografii roku mogła nie odzwierciedlać opisanego w komentarzu problemu.

Gdyby nawet powyższe uchybienia wziąć w nawias, wybór pracy Jon and Alex na fotografię roku 2015 budzi ogromne zdziwienie wobec istnienia wielu fotografii spełniających wszystkie kryteria oceny oraz w kontekście istnienia klauzuli 2 kodeksu etycznego konkursu, która mówi, że uczestnicy „nie mogą celowo przyczyniać się ani zmieniać sceny, którą przedstawiają poprzez odtworzenie lub inscenizację wydarzeń [lub] w jakikolwiek sposób wpływać na scenę lub udzielać wskazówek podmiotowi" (https:// www.worldpressphoto.org/programs/contests/photo-contest/verification-process/28610, dostęp: 26.08.2019). Jest kwestią niepodlegającą dyskusji, że w przypadku buduarowej sceny z prywatnego apartamentu w Sankt Petersburgu istnieją racjonalne argumenty za tym, by chcieć zweryfikować jej „dokumentalność”.

Wobec istnienia wielu prac posiadających ściśle dokumentalny charakter, które znalazły się w ostatniej rundzie konkursu, tym bardziej zastanawia, że praca Jon and Alex mogła z nimi konkurować jako praca o takim właśnie charakterze. Należy sobie uświadomić, że zdystansowała ona np. tak ortodoksyjną pod względem dokumentalnym fotografię dokumentalną jak Rescue Operation autorstwa Massimo Sestiniego, ukazującą łódź wypełnioną poza wszelkie granice rozsądku i bezpieczeństwa uchodźcami z Libii. Analiza syntaktyczna i semiotyczna obrazu Sestiniego pozwala w jednoznaczny sposób potwierdzić zgodność dwóch aspektów przekazu: zawartych w samym obrazie oraz w komentarzu określającym suche dane faktograficzne, co do których brak jest wątpliwości, że są spójne z tym, co widać na fotografii. 
Powyższy przypadek wskazuje na wyraźną chęć promowania treści związanych z problematyką LGBT przystających jedynie w bardzo luźny sposób do obrazu, które z nim powiązano w sztuczny sposób za pomocą komentarza, co obyło się kosztem innych utworów, odzwierciedlających „wydarzenia lub problemy o wielkim znaczeniu dziennikarskim" w 2015 r. Zastanawia cynizm, z jakim dokonano oceny. Polega on na zwróceniu uwagi opinii publicznej na problem, który - jak ukazuje to wypromowana fotografia nie domaga się od społeczeństw zaangażowania się w jego rozwiązanie $z$ takim przynagleniem do działania jak choćby w przypadku realnego przyjścia z pomocą tonącym w otchłaniach morskich czy ginącym w wyniku agresji militarnych. Ich wołanie o pomoc, pomimo zaangażowania się wielu fotografów w upublicznienie tych problemów, nie zostało na skutek stronniczych działań jury World Press Photo usłyszane.

Kończąc wątek dotyczący promocji nowych modeli kulturowych, należy zaznaczyć, że fotografie autorów podejmujących problematykę LGBT na przestrzeni badanego okresu były również obecne w innych edycjach konkursu. Gdy zestawiliśmy je z fotografiami podejmującymi problematykę rodzinną, przyjmując kryterium statystyczne, okazało się, że fotografii tych było przynajmmniej dwudziestokrotnie mniej niż zdjęć podejmujących wątki rodzinne. Świadczy to o braku zainteresowań fotografów tematyką LGBT, co nie oznacza, że ta proporcja nie ulegnie zmianie pod wpływem opiniotwórczych gremiów.

\section{What Remains, czyli o odporności obrazu na manipulacje medialne}

Temat rodziny jako taki nie jest reprezentowany w kategoriach tematycznych World Press Photo, jednakże w tym konkursie jest wystarczająco dużo powodów, by zgłaszać zdjęcia o tej tematyce, ponieważ zakresowo mieszczą się one w większości kategorii. Wśród wysoko nagradzanych prac stanowią one pokaźną część wszystkich realizacji, choćby z tego powodu, że rozmaite współczesne problemy społeczne, polityczne, obyczajowe i kulturowe dotykają kwestii rodzinnych. W takich przypadkach tematyka rodzinna powiązana jest np. z tematyką wojenną, społeczną lub dotyczącą katastrof, kataklizmów i klęsk żywiołowych. Co roku zgłaszana jest do konkursu bardzo duża ilość prac, które odzwierciedlają problematykę rodzinną w kontekście wymienionych problemów. Co roku pojawiają się prace, które zadedykowane są również wyłącznie problematyce rodzinnej, odzwierciedlając całą gamę możliwych dramatów, problemów i napięć związanych z codzienną egzystencją. Rzadziej - w skali 18 lat było kilkanaście takich przypadków - autorzy fotografii ukazywali „zwyczajną” stronę wizerunku współczesnej rodziny.

W roku 2015, w którym doszło do opisanego wyżej przypadku niefortunnego werdyktu jury, drugą nagrodę w kategorii Daily Life zdobyła właśnie taka realizacja ukazująca rodzinę w kategoriach zwyczajności. Jej autorem jest fotograf z Bangladeszu Sarker Protrick, który zgłosił do konkursu dziesięciozdjęciową pracę zatytułowaną What $R e-$ mains. Przedmiotem fotograficznej rejestracji byli dziadkowie fotografa John i Prova. Realizacja Protricka powstawała na przestrzeni lat 2011-2014 i jest opowieścią w konwencji storytelling. Opowiedziana przez niego historia jest prostym ikonicznym opisem 


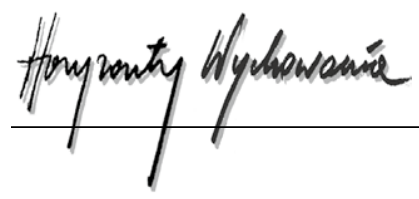

zwyczajnych egzystencjalnych chwil, które zostały przez niego dopowiedziane słowami komentarza. Oto kilka przykładów takich opisów, które przedstawiamy w porządku chronologicznym, w jakim zostały wykonane fotografie (zestaw autora został skomponowany według innego klucza): „8 grudnia 2011. John goli się pewnego ranka”; „17 stycznia 2012. Prova po kąpieli siada na łóżku”; „18 stycznia 2012. Ostatnie zdjęcie Johna i Provy razem”; „30 stycznia 2012. Obraz Jezusa Chrystusa wisi nad lodówką”; „25 lipca 2012. Prova leży w łóżku na kilka dni przed śmiercią" (https://www.worldpressphoto.org/programs/contests/photo-contest/winners/2015, dostęp: 03.08.2019).

W związku z tymi lakonicznymi opisami, będącymi czystym stwierdzeniem faktów, które odzwierciedlają zdjęcia, zasadne wydaje się postawienie pytania o sens opowieści Protricka. Skłania do tego sam autor, który w jednym z komentarzy do zdjęć wyjaśnia również, jakie kierowały nim motywacje, by podjąć temat: „To było po południu. Siedziałem na kanapie mojego dziadka. Drzwi były lekko otwarte i widziałem światło wpadające między białe drzwi i białe ściany. Nagle wszystko zaczęło mieć sens" (https://www.worldpressphoto.org/programs/contests/photo-contest/winners/2015, dostęp: 03.08.2019). Impresja autora musiała być niezwykle silna, skoro na rejestrowanie sytuacji widocznych na fotografiach poświęcił on aż kilka lat. Na uwagę zasługuje fakt, że znaczenia, jakie autor zakodował w strukturze obrazu, dają się odczytać w bezpośrednim odbiorze. Zamysł autora staje się czytelny po dokonaniu analizy syntaktycznej i semantycznej tej struktury. Ze względu na ramy objętościowe artykułu skupimy się przede wszystkim na jednej fotografii z tego zestawu, ukazującej babcię fotografa leżącą w łóżku „na kilka dni przed śmiercią".

Istotne dla naszej charakterystyki jest to, że podobnie jak pozostałe zdjęcia cyklu, omawiana fotografia została utrzymana w bardzo jasnej, prześwietlonej światłem tonacji. Wszystkie elementy obrazu, którymi są: fragmenty otoczenia łóżka, elementy pościeli oraz postać znajdująca się w centrum, zostały zakomponowane w sposób frontalny i ograniczone ciasnym kadrem. To ujęcie wywołuje skojarzenie $z$ inną fotografią, jedną z dziesięciozdjęciowej opowieści Protricka, na której widnieje wiszący nad lodówką w mieszkaniu jego dziadków obraz Jezusa Chrystusa, także zakomponowany frontalnie i posiadający wiele wspólnych cech formalnych z omawianą fotografią. Jest to czytelna sugestia autora, by treść analizowanej fotografii odczytywać w powiązaniu ze znaczeniami, jakie niesie wizerunek Chrystusa z mieszkania Johna i Provy, który towarzyszył im w ich codziennych, egzystencjalnych zmaganiach. Nie może być bez znaczenia, że ten konkretny wizerunek jawi się jako obraz Chrystusa przekraczającego i przezwyciężającego granice śmierci, co w szerszym zakresie należy odczytać w kategoriach przejścia, dla którego śmierć jest jedynie granicą ${ }^{2}$.

\footnotetext{
${ }^{2}$ Do takiej interpretacji upoważnia świadomość, że dziedzictwo obrazu podlega podobnym uwarunkowaniom co dziedzictwo literatury, które funkcjonuje w obrębie tej samej kultury. W obszarze tej kultury respektuje się $\mathrm{np}$. zasady intertekstualności tekstów w literaturze, które są analogiczne do powtarzalnych w dziejach obrazu ikonicznych motywów posiadających silne konotacje znaczeniowe.
} 
Godne uwagi jest to, że sugestie autora są sugestiami o charakterze ikonicznym, zatem adekwatne dla wypowiedzi z dziedziny obrazu, do której przecież fotografia przynależy. Istotne jest również to, że autor pozostawia odbiorcy wolność w interpretacji dzieła. Jeśli możemy dokonać jej w taki sposób, jak wyżej to zostało uczynione, to dlatego, że zakodowana w obrazach informacja umożliwia takie odczytanie przesłania autora.

Patrząc z punktu widzenia syntaktyki i semiotyki obrazu, fotografie Protricka stają się czytelne dzięki umiejętnemu posłużeniu się środkami wyrazu, które są równie proste, co sama jego opowieść. To m.in. stanowi o wartości i komunikatywności tej pracy. Fotograf z Bangladeszu uczy nas w ten sposób, w jaki sposób odpowiedzialnie kodować obraz, tak by mógł stać się on nośnikiem treści zawartych w jego strukturze. Godne uwagi jest również to, że autor zestawu What Remains nie uchyla się przed zobowiązaniami wobec odbiorcy jego przekazu, jakie posiada każdy autor działający w sferze medialnej. Najkrócej rzecz ujmując, zobowiązania te nakazują podtrzymywać spuściznę kulturową, która ukształtowała wartości humanistyczne naszej cywilizacji.

\section{Wyniki analizy}

Z przeprowadzonej analizy wynika, że promocja nowych modeli kulturowych, które w niniejszym artykule dotyczyły problematyki LGBT, odbywa się z naruszeniem reguł przyjmowanych dotąd przez media jako standardowe, na co wskazuje omawiany przykład głównej nagrody World Press Photo 2015. W tym przypadku nadużyć dokonano na poziomie decyzyjnym, w arbitralny sposób promując fotografię, która nie spełniała kryteriów konkursu. Gremium oceniające zignorowało także faktyczną treść zawartą w strukturze obrazu, a oceny dokonano na podstawie komunikatu słownego zawartego w komentarzu do zdjęć. Odbyło się to kosztem obniżenia rangi innych nośnych społecznie zagadnień. Ponieważ powyższy przypadek należy określić jako wyraźną manipulację dokonaną przez gremium oceniające, należy podać w wątpliwość rzetelność ocen także innych edycji konkursu, zwłaszcza że jego bardzo luźne i zbyt ogólnikowe reguły to umożliwiają. Stwierdzić należy jednocześnie, że w szerszej skali ostatnich 18 edycji konkursu „alternatywne” modele kulturowe nie cieszyły się zainteresowaniem przeważającej części fotografów zgłaszających swoje prace do konkursu, odmiennie aniżeli w przypadku tematyki rodzinnej.

\section{Wnioski}

Chociaż na gruncie fotografii prasowej na poziomie dokonywania ocen efektów wypracowanych przez fotografów czyni się wysiłki zmierzające do degradowania wizerunku rodziny, to na poziomie samego obrazu, rozumianego jako przekaz informacji, wizerunek rodziny nie podlega degradacji. Sztuczne promowanie nieobecnych dotąd na dużą skalę w kulturze modeli kulturowych nie sprawdza się więc w obszarze obrazu. 


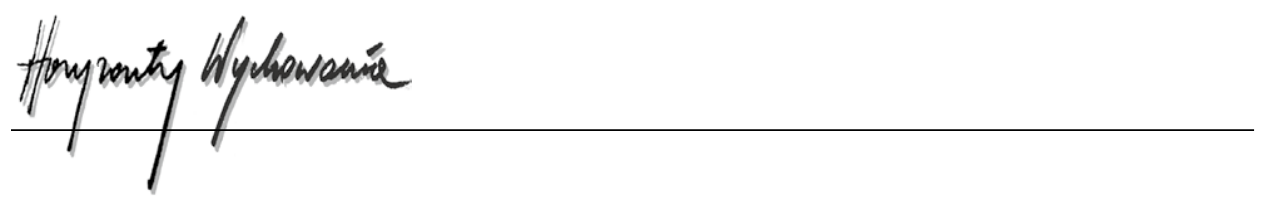

Należy zatem stwierdzić, że fotografia prasowa jest bardziej odporna na manipulacje niż przekazy słowne. Wynika to z dwóch powodów: pierwszym są właściwości samej fotografii dokumentalnej, którą dużo trudniej manipulować na poziomie struktury treści aniżeli w przypadku analogicznych przekazów formułowanych na poziomie słowa, drugim jest to, że fotograf w swojej pracy nad przekazem medialnym zmuszony jest mierzyć się $z$ realnością. Warto też nadmienić, że świat fotografów wydaje się w mniejszym stopniu podatny na konformistyczne zachowania i presję otoczenia aniżeli świat ich kolegów posługujących się piórem, o czym świadczą cały czas realizacje tych pierwszych, wykonywane nierzadko z narażeniem własnego życia, a także za cenę oddania własnego życia.

\section{BibliografiA}

Arnheim, R. (1978). Sztuka i percepcja wzrokowa. Psychologia twórczego oka. Warszawa: Wydawnictwa Artystyczne i Filmowe.

Arnheim, R. (2011). Myślenie wzrokowe. Gdańsk: słowo/obraz terytoria.

Berger, J. (1999). O patrzeniu. Warszawa: Aletheia.

Didi-Huberman, G. (2011). Przed obrazem. Gdańsk: słowo/obraz terytoria.

Porębski, M. (1986). Sztuka a informacja. Kraków, Wrocław: Wydawnictwo Literackie.

Strzemiński, W. (1958). Teoria widzenia. Kraków: Wydawnictwo Literackie.

Treppa, Z. (2012). Myślenie obrazem w fotografii. Gdańsk: Czysty Warsztat.

Waligórska, A. (2011). Sugestia i perswazja. Psychologia narracji wizualnej w sztuce i reklamie. Warszawa: SWPS

Wunenburger, J.-J. (2011). Filozofia obrazów. Gdańsk: słowo/obraz terytoria.

Źródła internetowe

World Press Photo Contest. History. Pozyskano z: https://www.worldpressphoto.org/programs/ contests/photo-contest/history/28612 (dostęp: 09.08.2019).

World Press Photo Contest. Judging Process. Pozyskano z: https://www.worldpressphoto.org/ programs/contests/photo-contest/judging-process/28600 (dostęp: 13.08.2019).

World Press Photo Contest. Winners 2015. Pozyskano z: https://www.worldpressphoto.org/programs/contests/photo-contest/winners/2015 (dostęp: 26.08.2019).

Fact-checking regulaminu World Press Photo. Pozyskano z: https://www.worldpressphoto.org/ programs/contests/photo-contest/verification-process/28610 (dostęp: 26.08.2019).

World Press Photo Contest. Winners 2015. Pozyskano z: https://www.worldpressphoto.org/programs/contests/photo-contest/winners/2015 (dostęp: 03.08.2019).

\section{Copyright and License}

This article is published under the terms of the Creative Commons Attribution - NoDerivs (CC BY- ND 4.0) License http://creativecommons.org/licenses/by-nd/4.0/ 